\title{
Prebiotic Inulin Supplementation and Peripheral Insulin Sensitivity in adults at Elevated Risk for Type 2 Diabetes: A Pilot Randomized Controlled Trial
}

\author{
Cassie M. Mitchell ${ }^{1,2,3}$, Brenda M. Davy ${ }^{1,2}$, Monica A. Ponder ${ }^{2,4}$, Ryan P. McMillan ${ }^{1}$, Michael D. Hughes ${ }^{4}$, \\ Matthew W. Hulver ${ }^{1,2}$, Andrew P. Neilson ${ }^{5}(\mathbb{D})$ and Kevin P. Davy ${ }^{1,2, *}$
}

check for updates

Citation: Mitchell, C.M.; Davy, B.M.; Ponder, M.A.; McMillan, R.P.

Hughes, M.D.; Hulver, M.W.; Neilson,

A.P.; Davy, K.P. Prebiotic Inulin

Supplementation and Peripheral

Insulin Sensitivity in adults at

Elevated Risk for Type 2 Diabetes:

A Pilot Randomized Controlled Trial.

Nutrients 2021, 13, 3235. https://

doi.org/10.3390/nu13093235

Academic Editor: Daniel Lamport

Received: 19 July 2021

Accepted: 3 September 2021

Published: 17 September 2021

Publisher's Note: MDPI stays neutral with regard to jurisdictional claims in published maps and institutional affiliations.

Copyright: (c) 2021 by the authors. Licensee MDPI, Basel, Switzerland. This article is an open access article distributed under the terms and conditions of the Creative Commons Attribution (CC BY) license (https:/ / creativecommons.org/licenses/by/ $4.0 /)$.
1 Department of Human Nutrition, Foods, and Exercise, Virginia Tech, Blacksburg, VA 24061, USA; casmitch@vt.edu (C.M.M.); bdavy@vt.edu (B.M.D.); mcmillr@vt.edu (R.P.M.); hulvermw@vt.edu (M.W.H.)

2 Translational Obesity Research Interdisciplinary Graduate Education Program, Virginia Tech, Blacksburg, VA 24061, USA; mponder@vt.edu

3 Obesity and Diabetes Clinical Research Section, Phoenix Epidemiology and Clinical Research Branch, National Institute of Diabetes and Digestive and Kidney Diseases, Phoenix, AZ 85016, USA

4 Department of Food Science and Technology, Virginia Tech, Blacksburg, VA 24060, USA; michah3@vt.edu

5 Plants for Human Health Institute, North Carolina Research Campus, North Carolina State University, Kannapolis, NC 28081, USA; aneilso@ncsu.edu

* Correspondence: kdavy@vt.edu

\begin{abstract}
Prediabetes affects 84.1 million adults, and many will progress to type 2 diabetes (T2D). The objective of this proof-of-concept trial was to determine the efficacy of inulin supplementation to improve glucose metabolism and reduce T2D risk. Adults $\left(n=24 ; \mathrm{BMI}: 31.3 \pm 2.9 \mathrm{~kg} / \mathrm{m}^{2}\right.$; age: $54.4 \pm 8.3$ years) at risk for T2D were enrolled in this controlled feeding trial and consumed either inulin (10 g/day) or placebo (maltodextrin, $10 \mathrm{~g} /$ day) for six weeks. Assessments included peripheral insulin sensitivity, fasting glucose, and insulin, HOMA-IR, in vivo skeletal muscle substrate preference, Bifidobacteria copy number, intestinal permeability, and endotoxin concentrations. Participant retention was $92 \%$. There were no baseline group differences except for fasting insulin $(p=0.003)$. The magnitude of reduction in fasting insulin concentrations with inulin $(p=0.003$, inulin $=\Delta-2.9$, placebo $=\Delta 2.3)$ was attenuated after adjustment for baseline concentrations $(p=0.04)$. After adjusting for baseline values, reduction in HOMA-IR with inulin (inulin $=\Delta-0.40$, placebo $=\Delta 0.27 ; p=0.004$ ) remained significant. Bifidobacteria $16 \mathrm{~s}$ increased $\left(p=0.04\right.$; inulin $=\Delta 3.1 \mathrm{e}^{9}$, placebo $\left.=\Delta-8.9 \mathrm{e}^{8}\right)$ with inulin supplementation. Despite increases in gut Bifidobacteria, inulin supplementation did not improve peripheral insulin sensitivity. These findings question the need for larger investigations of inulin and insulin sensitivity in this population.
\end{abstract}

Keywords: dietary fiber; prebiotics; inulin; diabetes; metabolism; gut microbiota

\section{Introduction}

The prevalence of type 2 diabetes (T2D) among U.S. adults is estimated to be $13 \%$, and it is the 7th leading cause of deaths in the US [1]. Prediabetes is a condition defined by impaired glucose tolerance (IGT), impaired fasting glucose (IFG), or a hemoglobin A1c (HbA1c) above normal but below the threshold indicative of T2D [1,2]. In 2018, the estimated number of U.S. adults with prediabetes was 88 million, and of these individuals, only $15.3 \%$ reported that a healthcare provider informed them of this diagnosis [1]. Although individual awareness of prediabetes has more than doubled from $6.5 \%$ since 2005 , most people remain unaware of their metabolic condition [1,3-5]. The rising prevalence of prediabetes and T2D is a national health problem that warrants research focused upon T2D prevention strategies $[1,3,4]$.

Lifestyle modification strategies for prevention of T2D include weight loss of 5-10\% total body weight, 30 min of moderate physical activity (PA) at least 5 days/week, and 
consumption of dietary patterns focused on fruits, vegetables, and whole grains [6,7]. However, the impact of specific dietary modifications and their subsequent influence on T2D risk are not well understood. Human and animal studies suggest that consumption of a western diet, characterized by a high intake of dietary fat and sugar, may negatively impact gut microbiome composition by reducing bacterial taxa associated with gut health, increase intestinal permeability, and lead to metabolic endotoxemia [8-10]. In turn, metabolic endotoxemia is associated with the development of a low-grade chronic inflammatory state, obesity, and insulin resistance in rodents $[8,10,11]$. In humans, fasting endotoxin concentrations are higher in individuals with prediabetes and T2D compared with normoglycemic individuals [12], and endotoxemia is associated with an increased risk of prevalent and incident T2D [13]. Importantly, endotoxin induces an inflammatory response, which reduces insulin signaling and glucose transport in human skeletal muscle [14]. Furthermore, low dose endotoxin, at concentrations consistent with metabolic endotoxemia, activate skeletal muscle toll-like receptor 4 and causes a state of metabolic inflexibility consistent with that observed in obesity and T2D.

Evidence suggests that the microbiome can be selectively modulated in a little as 5 days and that consumption of the prebiotic inulin may influence gut microbiome composition and function by selectively targeting bacteria beneficial for gut health and barrier function [15-17]. One way that prebiotics may improve gut health is by promoting increases in several bacterial taxa, such as Bifidobacteria $[16,18]$. In turn, this might lead to improved gut-barrier function, reduced endotoxin concentration, lower levels of pro-inflammatory cytokines, and reduced risk of T2D with inulin consumption [15,16,19-21].

Supplementation with the prebiotic inulin may be a simple and efficacious strategy to decrease the risk for T2D. However, there is limited evidence evaluating the mechanisms by which prebiotic supplementation with inulin may alter glucose metabolism and diminish T2D risk in humans [21,22]. Therefore, the objective of this proof-of-concept pilot randomized controlled trial (RCT) was to evaluate this possibility using a rigorous controlled feeding design [23]. We hypothesized that inulin supplementation would improve peripheral insulin sensitivity and in vivo skeletal muscle substrate preference in adults at risk of T2D [23]. We further hypothesized that improvements, if observed, would be associated with increased abundance of Bifidobacteria as well as reduced intestinal permeability and circulating endotoxin concentrations.

\section{Materials and Methods}

\subsection{Participants}

Detailed rationale and methods for this pilot RCT were previously described [23]. An overview of our study protocol is presented in Figure 1. Briefly, 946 individuals were screened for participation, and 24 individuals were consented, screened, and randomized in this trial (Figures 1 and 2). Participants were between $40-75$ years old with a body mass index (BMI) between $25-39.9 \mathrm{~kg} / \mathrm{m}^{2}$ and sedentary to recreationally active [24]. Body weight was stable for all participants 6 months prior to study enrollment, and none of the participants had taken antibiotics, fiber supplements, multivitamin supplements, or antioxidants within the 3 months preceding enrollment. In addition, all participants met 1 or more of the following criteria established for elevated T2D risk: American Diabetes Association (ADA) risk screener score $\geq 5$; hemoglobin A1c (HbA1c) between 5.7-6.4 mg/dL; fasting blood glucose (FBG) between 100-125 mg/dL; or 2-h oral glucose tolerance test (OGTT) value between 140-200 mg/dL [2,25]. This trial was registered on clinicaltrials.gov (Identifier: NCT02346838) and approved by Virginia Tech. Institutional Review Board (protocol \#13-694). All participants provided verbal and written informed consent prior to participation. 


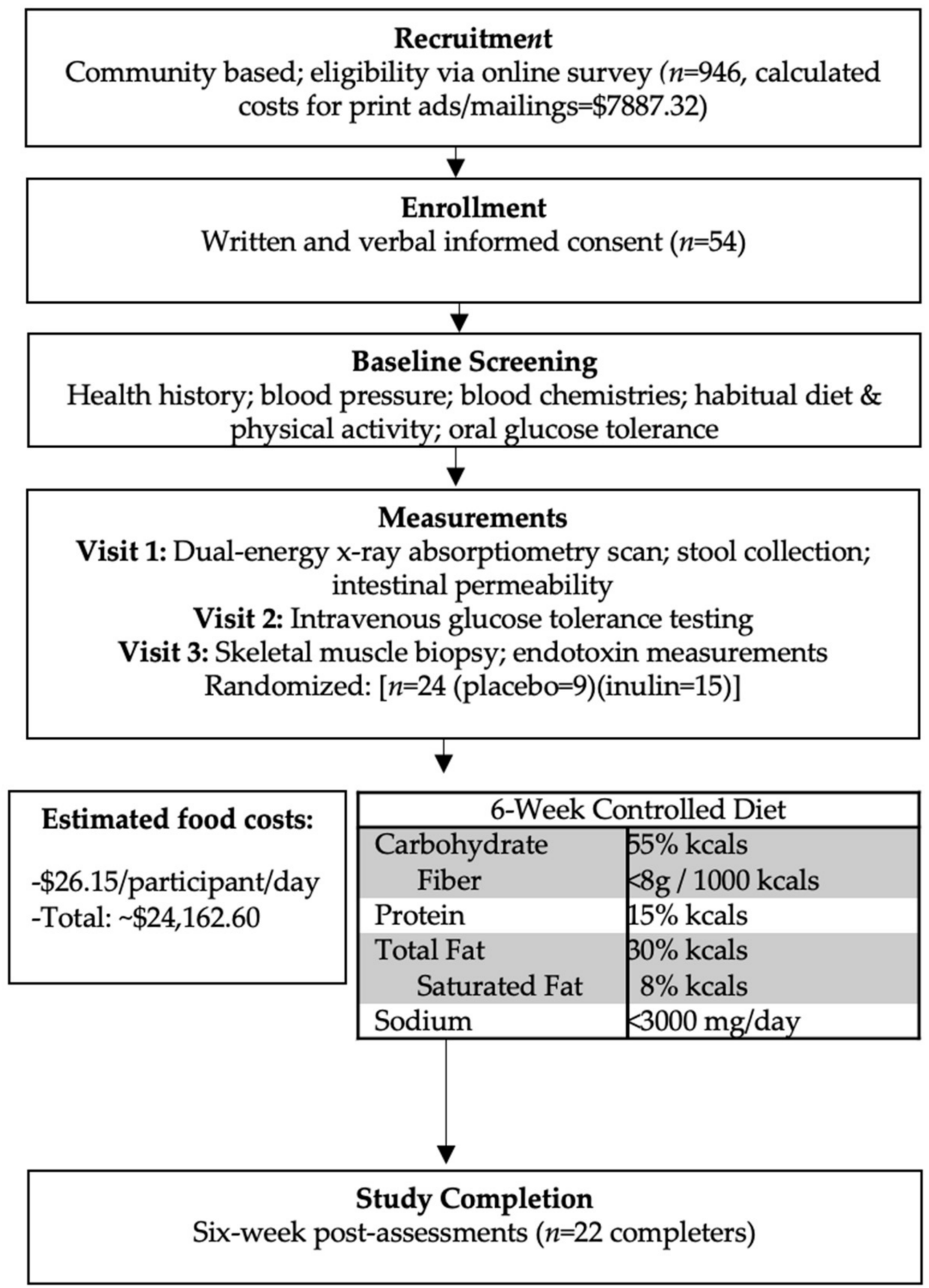




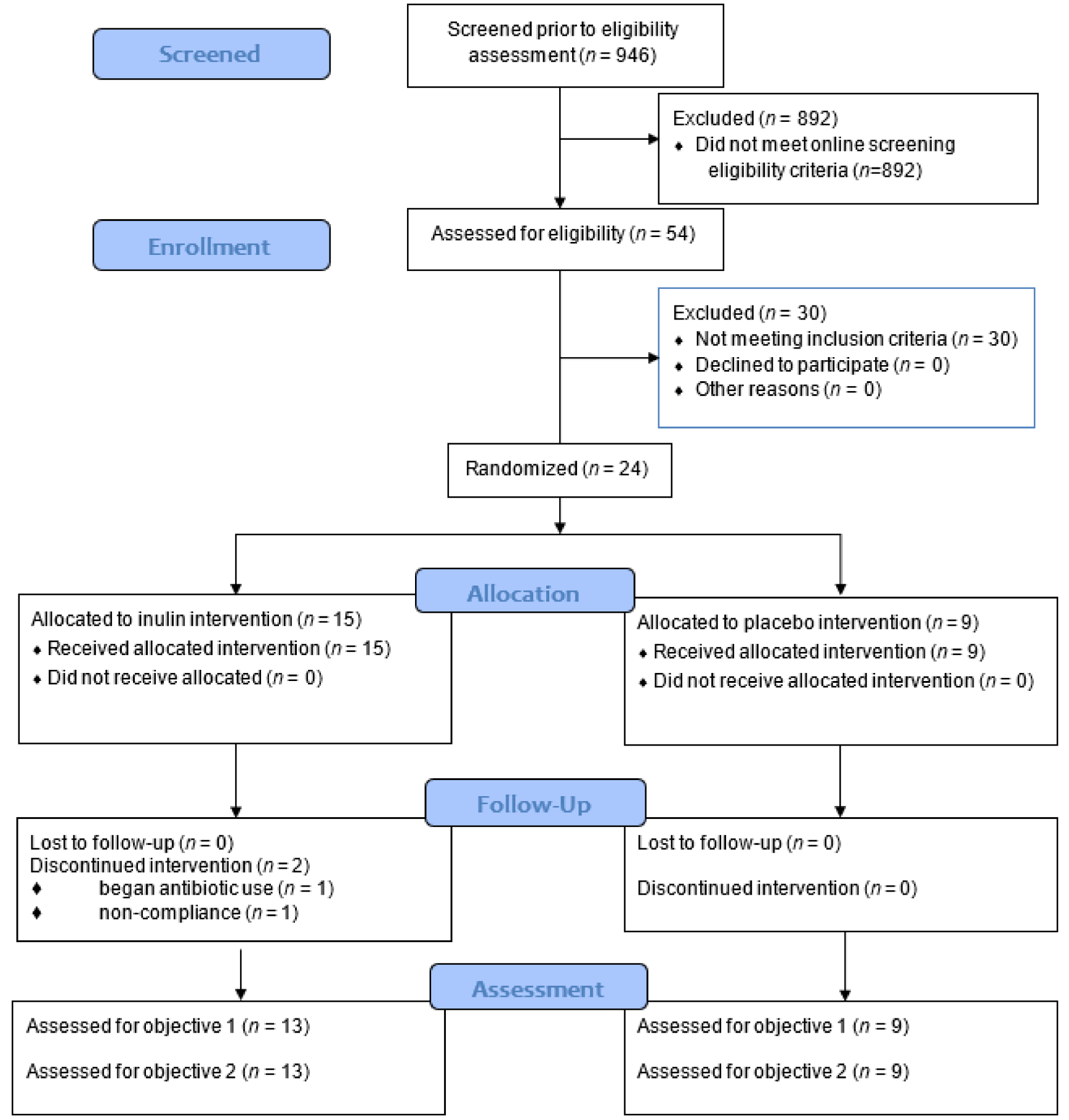

Figure 2. CONSORT Flow Diagram (Pilot Extension) [26].

\subsection{Experimental Design}

This trial was a randomized, double-blind placebo-controlled feeding trial of inulin (10 g/day [Frutafit ${ }^{\circledR}$ IQ, Sensus American, Inc., Lawrenceville, NJ, USA; 100\% chicory root inulin, DP 9-12]) or placebo (maltodextrin; $10 \mathrm{~g} /$ day) supplementation for 6 weeks. The inulin dose selected was based on tolerability and anticipated metabolic benefit [27]. Randomization and enrollment, stratified by sex, was performed using a computerized random number generator by an individual (BMD) not involved in the collection or analysis of the data. Measurements were performed at baseline (visits 1-3; Figure 1) and following the 6-week intervention in the Human Integrative Physiology Laboratory. All participants 
consumed an isocaloric standardized diet ( $55 \%$ carbohydrate [ $<8 \mathrm{~g}$ fiber $/ 1000 \mathrm{kcals}$ ], 30\% fat [ $8 \%$ saturated fat], $15 \%$ protein) (Figure 1, Table S1) with daily supplementation of either inulin or placebo until follow-up testing was completed. Supplementation vials were labeled A or B to keep study personnel and participants blinded to group assignment. Participants reported to the Metabolic Kitchen and Dining Laboratory a minimum of 3 days/week to collect provided meals and undergo body weight checks. During these visits, participants consumed a supervised breakfast meal, which included consumption of the $10 \mathrm{~g}$ supplement (inulin or placebo) dispersed in 16 fluid ounces of water and was then provided with coolers containing their study food for the next $48 \mathrm{~h}$. Coolers from the previous 2 days were collected by research personnel, and any uneaten food was weighed.

\subsection{Experimental Testing}

All testing sessions during screening, baseline, and week 6 were completed between the hours of 5:00 a.m. and 10:00 a.m. in the fasted state. At baseline testing, participants were provided a list of instructions that included abstaining from alcohol, caffeine, and physical activity (PA) for $48 \mathrm{~h}$ prior to the scheduled testing visit. Participants were free from self-reported acute illness for a minimum of 2 weeks prior to all scheduled testing visits.

\subsection{Measurements and Procedures}

Body weight and height were measured on a digital scale (nearest $0.1 \mathrm{~kg}$ ) and mounted stadiometer, respectively (Scale-Tronix Model 5002, White Plains, NY, USA). Body composition was measured utilizing dual-energy $x$-ray absorptiometry (General Electric, Lunar Digital Prodigy Advance, software version 8.10e Madison, WI, USA). Blood chemistries were performed in a CLIA certified laboratory (Solstas Lab Partners, Roanoke, VA, USA). Blood pressure was measured using an automated oscillometric device (GE Dynamap Carescape V100, GE Healthcare, Chicago, IL, USA). Habitual dietary intake was assessed using self-reported 4-day food intake records. A trained research technician provided study participants with written and verbal instruction for accurately measuring and recording food intake. The Nutrition Data Systems for Research software (NDS-R 2014, University of Minnesota, Minneapolis, MN, USA) was used to estimate energy and macronutrient content from the dietary records. Habitual physical activity (PA) level was measured by an accelerometer (GT1M, Actigraph, Pensacola, FL, USA) worn for 4 consecutive days before and after the intervention.

Peripheral insulin sensitivity, i.e., insulin sensitivity index (SI), glucose effectiveness $(\mathrm{Sg})$, acute insulin response to glucose (AIRg), and disposition index (DI) were measured using a frequently sampled intravenous glucose tolerance test (IVGTT) with Bergman's minimal model (MINMOD Millennium) [28], as described previously [23,29]. IVGTT findings were presented for 8 participants in the placebo group and 9 in the inulin group due to missing blood samples that precluded performing the minimal model analysis. Briefly, an intravenous catheter was placed, and baseline blood samples were obtained at $[(\mathrm{I})=-10$ and $-1 \mathrm{~min}$. Dextrose $(0.3 \mathrm{~g} / \mathrm{kg} ; 50 \%$ solution $)$ was injected at time 0 and insulin $(0.025 \mathrm{U} / \mathrm{kg})$ was injected at $(t)=20 \mathrm{~min}$. Subsequent samples were obtained at $(t)=1,2,3,4,5,6,7,8,10,12,14,16,18,22,23,24,25,27,30,40,50,60,70,80,90,100$, 120,150 , and $180 \mathrm{~min}$ during the $3 \mathrm{~h}$ protocol. Plasma glucose samples were analyzed using a YSI Glucose Analyzer 2300 Stat Plus (Yellow Springs, OH, USA), and serum insulin concentration was analyzed via ELISA (ALPCO Diagnostics, Salem, NH, USA). HOMA-IR was calculated from fasting insulin and glucose concentrations according to Levy et al. [30].

Serum endotoxin concentrations were determined using the PyroGeneTM Recombinant Factor C Endotoxin Detection Assay (Lonza International, Basel, Switzerland). Lipopolysaccharide binding protein concentration was measured by ELISA (R\&D Systems, Minneapolis, MN, USA).

Skeletal muscle biopsies were obtained from the vastus lateralis using a modified Bergstrom needle technique with suction [31,32]. Glucose and pyruvate oxidation were 
evaluated by measuring ${ }^{14} \mathrm{C}-\mathrm{CO}_{2}$ production. Complete and incomplete fatty acid oxidation were assessed by measuring ${ }^{14} \mathrm{C}-\mathrm{CO}_{2}$ and acid soluble metabolites. Skeletal muscle substrate preference was determined by $\left[1-{ }^{14} \mathrm{C}\right]$ pyruvate oxidation with and without the availability of non-labeled palmitic acid. The suppressibility of pyruvate oxidation in the presence of palmitic acid compared to control (without palmitic acid) was expressed as the ratio of pyruvate oxidation-free fatty acids: pyruvate oxidation + free fatty acids. All substrate metabolism measures were assessed using skeletal muscle homogenates from biopsied tissue and were previously described [14,23,33,34]. In addition, citrate synthase and cytochrome-c oxidase mitochondrial enzyme activities were measured utilizing the biopsied muscle samples [35,36].

Stool collection kits (Omnigene gut for microbiome, Owatonna, ON, Canada) were provided to participants at each testing timepoint. Bacterial DNA was isolated from fecal samples using the QIAamp ${ }^{\circledR}$ PowerFecal ${ }^{\circledR}$ DNA Kit from QIAGEN (Hilden, Germany). All extractions from $0.25 \mathrm{~g}$ of feces were completed by manufacturer's instructions. The resulting elutions were then evaluated for DNA yield using a NanoDrop ${ }^{\mathrm{TM}} 2000$ Spectrophotometer (Waltham, MA, USA) and stored at $-80^{\circ} \mathrm{C}$.

The number of copies of Bifidobacterium 16s rRNA gene in each sample was quantified using quantitative real-time PCR methods using primer sets Bif164- $f$ ( $5^{\prime}$ - GGG TGG TAA TGC CGG ATG -3') and Bif662-r (5'- CCA CCG TTA CAC CGG GAA -3') [37-39]. Each reaction contained $50 \mathrm{ng} / \mu \mathrm{L}$ sample DNA, $15 \mathrm{uL}$ of qRT-PCR master mix (BioRAD SSOAdvanced ${ }^{\mathrm{TM}}$ Universal Inhibitor-Tolerant SYBR ${ }^{\circledR}$ Green Supermix), $2.5 \mu \mathrm{L}$ of Bif166-f primer, $2.5 \mu \mathrm{L}$ of Bif662-r primer, and filled to $30 \mu \mathrm{L}$ volume with nuclease-free water. qRT-PCR conditions were as follows: 1 cycle of amplification at $95^{\circ} \mathrm{C}$ for $3 \mathrm{~min}, 40$ cycles at $95{ }^{\circ} \mathrm{C}$ for $30 \mathrm{~s}, 62^{\circ} \mathrm{C}$ for $40 \mathrm{~s}$, and $72{ }^{\circ} \mathrm{C}$ for $1 \mathrm{~min}$. The melt curve was established by heating at $0.5^{\circ} \mathrm{C}$ increments from 62 to $95^{\circ} \mathrm{C}$. qRT-PCR assays were conducted using a BioRad (Hercules, CA, USA) CFX thermal cycler.

Samples were quantified based on extrapolation to a standard curve generated using g-block ${ }^{\circledR}$ Gene Fragments from Integrated DNA Technologies (Coralville, IA, USA) to serve as a standard curve. The gene fragments used were designed as copies of the genus specific Bifidobacteria 16S rDNA gene. G-block stock was diluted to $100 \mathrm{ng} / \mu \mathrm{L}$ using nuclease-free water, then pipetted into microcentrifuge vials in a serial 9-fold dilution from $10^{-1}$ to $10^{-8}$. $8.9 \times 10^{11}$ copies of the Bifidobacteria 16S rRNA gene were determined to be present in g-block ${ }^{\circledR}$ stock. Blanks containing nuclease-free water only were run as negative controls.

A defined mix of 4 sugar probes followed by $24 \mathrm{~h}$ urine collection to assess intestinal permeability were completed at each testing timepoint, and total urine volume was recorded. Intestinal permeability for the upper and lower gastrointestinal tract was calculated and analyzed as \% urinary excretion and excretion ratios of urinary sugars [40-44]. Sugars were measured by UPLC-MS as previously described [23]. Furthermore, intestinal permeability was divided into gastroduodenal (expressed as: $0-5 \mathrm{~h} \%$ sucrose excretion and sucrose-mannitol ratio), small intestinal (lactulose-mannitol ratio $0-5 \mathrm{~h}$ and 6-24 h), and colonic permeability (expressed as: $0-5 \mathrm{~h}$ and $6-24 \mathrm{~h} \%$ sucralose excretion and sucralosemannitol ratio). Plasma endotoxin concentrations were determined using the PyroGeneTM Recombinant Factor C Endotoxin Detection Assay (Lonza International).

\subsection{Adverse Events and Side Effect Monitoring}

During the controlled diet phase of the investigation, participants were instructed to alert study personnel of any atypical gastrointestinal symptoms or side effects (e.g., gas, bloating, or diarrhea), which were reported on a standardized questionnaire $[27,45]$.

\subsection{Calculations and Statistical Analyses}

Compliance to the controlled diet was calculated for each food provided to each participant for all 6 weeks (calculated as: [provided food weight—consumed weight]/provided weight $\times 100=\%$ compliance) . 
Independent $t$-tests were used to test for differences in baseline participant characteristics. Two-way repeated-measures analyses of variance were used to test for main effects for group, time, and the group $\times$ time interaction. Analyses of Covariance (ANCOVA) were utilized to adjust for baseline, where baseline and week- 6 were input into the ANCOVA model as the independent and dependent variables, respectively and inulin and placebo were included as independent classification variables. Pearson's product-moment correlations were used to assess relationships among variables. SPSS Statistical Software (version 26, 2019; IBM, Armonk, NY, USA) and SAS Enterprise Guide (version 7.1; IBM, Cary, NC, USA) was used for all analyses.

\subsection{Sample Size}

The purpose of this pilot trial was to establish proof-of-concept efficacy and to obtain preliminary data for a larger trial. We calculated the sample size needed to detect a physiologically and statistically significant improvement in insulin sensitivity with inulin supplementation using G*Power 3.1 [46]. With 2 groups, 2 repeated measures, and alpha $=0.05$, we estimated that we would have $90 \%$ power to detect a $20 \%$ increase in insulin sensitivity (effect size $=0.61$ ) with $n=24$ participants per group. However, the trial was terminated at the end of the funding period when an interim analysis was performed, indicating that the effect size for the change in peripheral insulin sensitivity was much smaller in magnitude (0.21) than originally estimated. The results of that analysis are presented herein.

\section{Results}

Of the 54 individuals who were consented and screened in the laboratory, 24 individuals met all inclusion criteria and were randomized (Figures 1 and 2). Recruitment costs were estimated to be $\sim \$ 8000$ ( $\sim 333$ per participant randomized; Figure 1). A total of 22 individuals completed the trial (92\% retention).

\subsection{Baseline Participant Characteristics}

Baseline characteristics are summarized in Table 1. There were no group differences in participant characteristics at baseline (all $p>0.05$ ) except fasting insulin concentration was higher $(p=0.027)$ in the inulin compared with the placebo group. Participants were primarily Caucasian females (65\%). All participants scored a 5 or higher on the ADA risk screener and were considered obese based upon BMI classification and body fat percentage.

Table 1. Baseline participant characteristics.

\begin{tabular}{ccc}
\hline Descriptives & Placebo $(\boldsymbol{n}=\mathbf{9})$ & Inulin $(\boldsymbol{n}=\mathbf{1 3})$ \\
\hline Sex & $\begin{array}{c}\text { Males }=3 \\
\text { Female }=6\end{array}$ & $\begin{array}{c}\text { Males }=5 \\
\text { Female }=8\end{array}$ \\
\hline Race & Caucasian $=9$ & $\begin{array}{c}\text { Caucasian }=12 \\
\text { African }=1\end{array}$ \\
\hline ADA Risk Score & $5 \pm 0$ & $5 \pm 0$ \\
\hline Age (years) & $54.2 \pm 3.2$ & $54.5 \pm 2.1$ \\
\hline Anthropometrics & & $169.2 \pm 3.0$ \\
\hline Height $(\mathrm{cm})$ & $168.7 \pm 3.0$ & $89.5 \pm 3.9$ \\
\hline Weight $(\mathrm{kg})$ & $89.3 \pm 3.0$ & $31.4 \pm 0.9$ \\
\hline BMI $\left(\mathrm{kg} / \mathrm{m}^{2}\right)$ & $31.2 \pm 0.8$ & $40.1 \pm 6.7$ \\
\hline Body fat $(\%)$ & $42.3 \pm 9.9$ &
\end{tabular}


Table 1. Cont.

\begin{tabular}{|c|c|c|}
\hline Descriptives & Placebo $(n=9)$ & Inulin $(n=13)$ \\
\hline \multicolumn{3}{|l|}{ Blood Chemistries and Blood Pressure } \\
\hline FBG (mg/dL) & $90 \pm 4$ & $96 \pm 4$ \\
\hline Fasting Insulin uIU/mL & $9 \pm 2$ & $15 \pm 2$ * \\
\hline 2-hr glucose $(\mathrm{mg} / \mathrm{dL})$ & $118 \pm 17$ & $121 \pm 12$ \\
\hline $\mathrm{HbA1c}(\%)$ & $5.7 \pm 0.1$ & $5.4 \pm 0.1$ \\
\hline $\mathrm{TC}(\mathrm{mg} / \mathrm{dL})$ & $209 \pm 10$ & $215 \pm 8$ \\
\hline HDL (mg/dL) & $57 \pm 6$ & $50 \pm 3$ \\
\hline $\mathrm{LDL}(\mathrm{mg} / \mathrm{dL})$ & $123 \pm 14$ & $138 \pm 9$ \\
\hline VLDL (mg/dL) & $29 \pm 7$ & $27 \pm 3$ \\
\hline $\mathrm{TG}(\mathrm{mg} / \mathrm{dL})$ & $147 \pm 33$ & $134 \pm 14$ \\
\hline $\mathrm{SBP}(\mathrm{mmHg})$ & $128 \pm 3$ & $130 \pm 3$ \\
\hline $\mathrm{DBP}(\mathrm{mmHg})$ & $79 \pm 3$ & $77 \pm 2$ \\
\hline \multicolumn{3}{|l|}{ Habitual Dietary Intake } \\
\hline Kcals & $2119 \pm 191$ & $2094 \pm 165$ \\
\hline Protein (grams) & $79 \pm 8$ & $98 \pm 6$ \\
\hline (\% energy) & $15 \pm 0$ & $19 \pm 0$ \\
\hline Carbohydrates (grams) & $258 \pm 24$ & $227 \pm 18$ \\
\hline (\% energy) & $49 \pm 1$ & $43 \pm 0$ \\
\hline Fats (grams) & $85 \pm 11$ & $92 \pm 9$ \\
\hline (\% energy) & $36 \pm 1$ & $40 \pm 0$ \\
\hline Dietary fiber (g) & $22 \pm 2$ & $17 \pm 2$ \\
\hline Soluble fiber (g) & $7 \pm 1$ & $7 \pm 1$ \\
\hline Pectins (g) & $2 \pm 0$ & $2 \pm 0$ \\
\hline Sodium (mg) & $3166 \pm 279$ & $3699 \pm 270$ \\
\hline
\end{tabular}

Data are mean \pm SEM descriptive statistics. Abbreviations used: ADA = American Diabetes Association $\mathrm{BMI}=$ body mass index; $\mathrm{FBG}=$ fasting blood glucose; $\mathrm{HbA} 1 \mathrm{c}=$ hemoglobin $\mathrm{A} 1 \mathrm{c} ; \mathrm{TC}=$ total cholesterol; $\mathrm{HDL}=$ high-density lipoproteins; $\mathrm{LDL}=$ low-density lipoproteins; $\mathrm{VLDL}=$ very low-density lipoproteins; $\mathrm{TG}=$ triglycerides; $\mathrm{SBP}=$ systolic blood pressure; $\mathrm{DBP}=$ diastolic blood pressure; kcals = kilocalories. ${ }^{*} p=0.027$.

\subsection{Controlled Diet}

The composition of the controlled diet is shown in Figure 1 and Table S1. Daily food costs were estimated to be $\$ 26.15$ per participant (Figure 1). Overall compliance to the controlled diet was $97.5 \%$ (inulin, $98 \%$ compliance; placebo, 97\% compliance). In addition, there were no changes in body weight or PA with the intervention (Figure S1 and Table S2; all $p>0.05)$.

\subsection{Side Effects}

One participant in each group ( 2 total) reported mild gastrointestinal side effects that included bloating and loose stool. However, these side effects resolved within $48 \mathrm{~h}$ of initial dosing.

\subsection{Insulin Sensitivity, Skeletal Muscle Substrate Oxidation, and Mitochondrial Enzyme Activities}

FBG did not change $(p>0.05)$ with the intervention in the placebo (baseline: $87 \pm 10 \mathrm{mg} / \mathrm{dL}, 6$ weeks: $85 \pm 8 \mathrm{mg} / \mathrm{dL}$ ) or inulin (baseline: $94 \pm 10,6$ weeks: $97 \pm 13 \mathrm{mg} / \mathrm{dL}$ ) group. However, fasting insulin concentrations and HOMA-IR declined in the inulin but not the placebo group (Figure 3). The magnitude of reduction in fasting insulin concentration was attenuated following adjustment for baseline concentrations; wherein, baseline was utilized as the independent variable $(p=0.04)$. The reduction in HOMA-IR 
was no longer significant after adjustment for baseline levels. There were no changes in SI or any of the other IVGTT-related variables following the intervention (Figure S2; all $p>0.05$ ). In addition, there were no changes in glucose oxidation, fat oxidation, pyruvate oxidation, or substrate preference in homogenates with the intervention (Table 2; all $p>0.05$ ). Skeletal muscle mitochondrial enzyme activities also remained unchanged $(p>0.05)$.
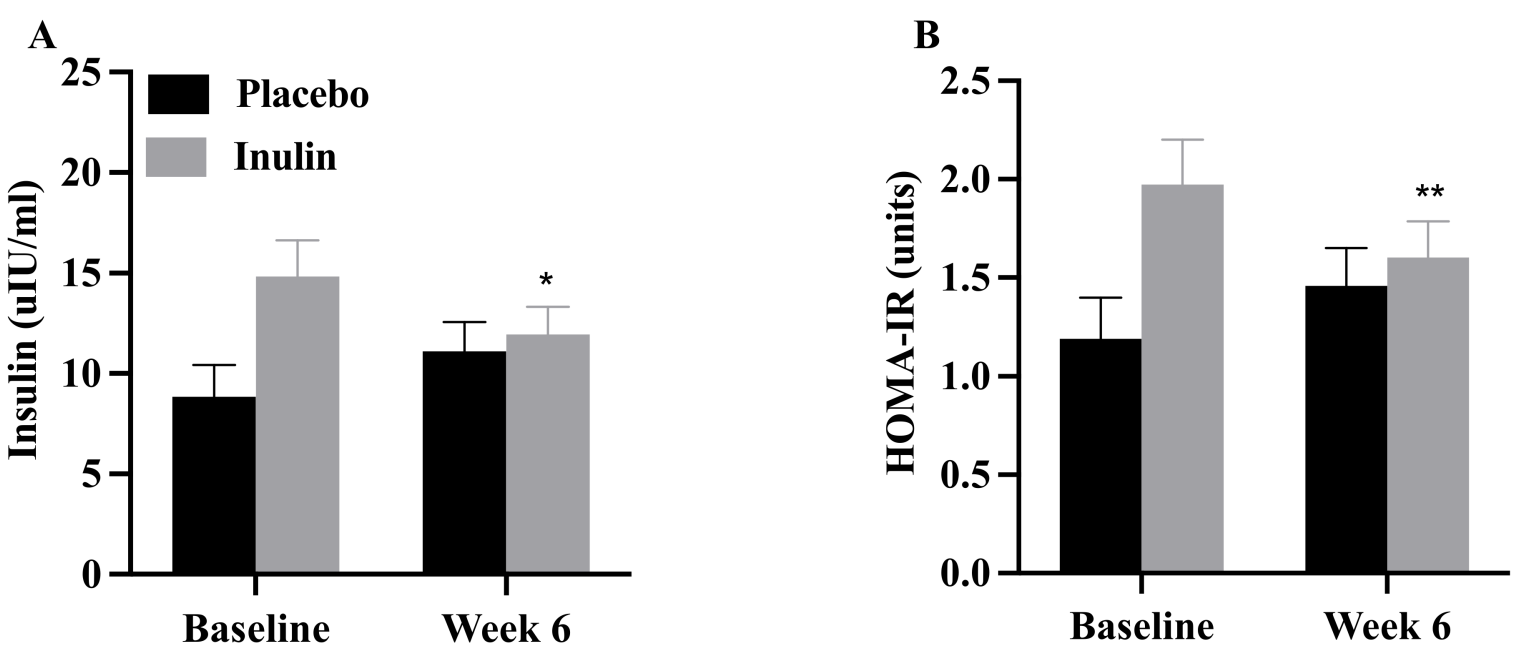

Figure 3. Values are mean \pm SEM. There was a significant reduction in (A) fasting insulin and (B) HOMA-IR in the inulin group. HOMA-IR = homeostatic model of assessment for insulin resistance. ${ }^{*} p=0.03 ;{ }^{* *} p=0.004$.

Table 2. Fasted participant skeletal muscle metabolism and mitochondrial enzyme variables before and after 6-weeks of supplementation with placebo or inulin.

\begin{tabular}{|c|c|c|c|c|c|}
\hline \multirow[t]{2}{*}{ Variable } & \multicolumn{2}{|c|}{ Placebo } & \multicolumn{2}{|c|}{ Inulin } & \multirow{2}{*}{$\begin{array}{c}\text { Interactions } \\
p \text {-Values }\end{array}$} \\
\hline & Baseline & Week 6 & Baseline & Week 6 & \\
\hline Glucose Oxidation & $5.8 \pm 1.0$ & $5.5 \pm 1.0$ & $5.3 \pm 1.0$ & $5.9 \pm 1.1$ & $p=0.90$ \\
\hline $\begin{array}{l}\text { Fatty Acid } \\
\text { Oxidation }\end{array}$ & $6.9 \pm 1.1$ & $7.4 \pm 0.7$ & $7.0 \pm 1.0$ & $7.6 \pm 1.0$ & $p=0.22$ \\
\hline $\begin{array}{l}\text { Pyruvate } \\
\text { Oxidation }\end{array}$ & $354.5 \pm 36.5$ & $339.9 \pm 45.9$ & $248.9 \pm 23.4$ & $285 \pm 29.6$ & $p=0.43$ \\
\hline $\begin{array}{l}\text { Metabolic } \\
\text { Flexibility }\end{array}$ & $32.4 \pm 3.8$ & $23.1 \pm 4.0$ & $22.5 \pm 4.4$ & $31.5 \pm 3.8$ & $p=0.07$ \\
\hline Citrate synthase & $52.5 \pm 8.2$ & $53.3 \pm 10.0$ & $41.6 \pm 7.6$ & $39.8 \pm 5.0$ & $p=0.52$ \\
\hline $\begin{array}{l}\text { Cytochrome-c } \\
\text { Oxidase }\end{array}$ & $139.1 \pm 25.0$ & $171.8 \pm 40.2$ & $102.7 \pm 20.7$ & $132.8 \pm 15.9$ & $p=0.50$ \\
\hline
\end{tabular}

All values are expressed as mean \pm SEM. All interactions, derived from 2-way repeated-measures ANOVA were non-significant $(p>0.05)$. Units for skeletal muscle metabolism are expressed as: ( $\mu \mathrm{mol} / \mathrm{mg}$ protein $/$ hour $)$. Metabolic flexibility is expressed as the ratio of pyruvate oxidation \pm free fatty acids.

\subsection{Bifidobacteria, Intestinal Permeability, and Endotoxin Concentrations}

There were no group differences in Bifidobacteria copy number, intestinal permeability, endotoxin or lipopolysaccharide binding protein concentrations at baseline (all $p>0.05$ ). Bifidobacteria increased with inulin supplementation but not in the placebo group (Figure 4A $(p=0.04))$. There were no changes in intestinal permeability (Table 3), plasma endotoxin concentration, or lipopolysaccharide binding protein concentration (Figure 4B,C (all $p>0.05)$ ). There was no significant correlation between changes in Bifidobacteria and any of the other outcome variables. 

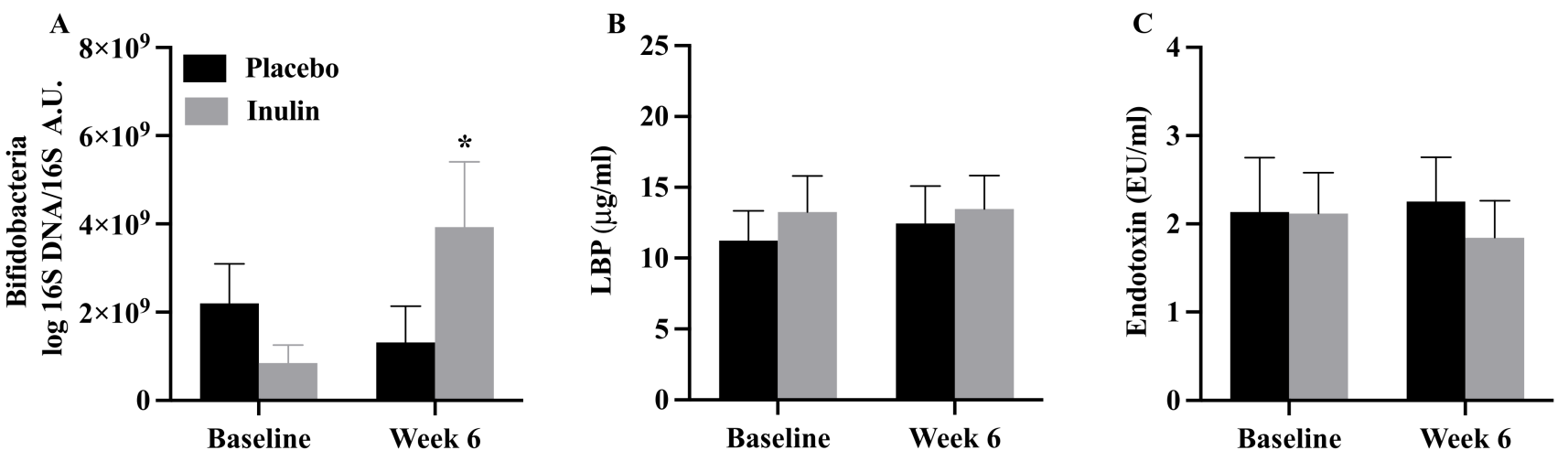

Figure 4. Values are mean \pm SEM. (A) Bifidobacteria increased following 6-weeks in the inulin, but not the placebo ( $p=0.04)$ following the intervention. There was no significant change in (B) lipopolysaccharide binding protein or (C) endotoxin concentration in the placebo or inulin groups (both $p>0.05$ ). LBP $=$ lipopolysaccharide binding protein. ${ }^{*} p=0.04$. 
Table 3. Intestinal permeability outcomes and change over time.

\begin{tabular}{|c|c|c|c|c|c|c|c|}
\hline \multirow[t]{2}{*}{ Variable } & \multicolumn{3}{|c|}{ Placebo } & \multicolumn{3}{|c|}{ Inulin } & \multirow{2}{*}{$\frac{\text { Interactions }}{p \text {-Values }}$} \\
\hline & Baseline & Week 6 & $\Delta$-Score & Baseline & Week 6 & $\Delta$-Score & \\
\hline \multicolumn{8}{|c|}{ Small intestine permeability } \\
\hline $0-5$ h (ratio) & $0.0117 \pm 0.001$ & $0.0096 \pm 0.0013$ & $-0.0021 \pm 0.0018$ & $0.0109 \pm 0.0014$ & $0.0090 \pm 0.0010$ & $-0.0018 \pm 0.0011$ & $p=0.88$ \\
\hline 6-24 h (ratio) & $0.0342 \pm 0.0065$ & $0.0266 \pm 0.0043$ & $-0.0076 \pm 0.0058$ & $0.0323 \pm 0.0053$ & $0.0218 \pm 0.0032$ & $-0.0105 \pm 0.0040$ & $p=0.68$ \\
\hline \multicolumn{8}{|c|}{ Gastroduodenal permeability } \\
\hline $0-5$ h $(\%)$ & $0.0241 \pm 0.0060$ & $0.0289 \pm 0.0160$ & $0.0048 \pm 0.0170$ & $0.0226 \pm 0.0041$ & $0.0326 \pm 0.0114$ & $0.0010 \pm 0.0010$ & $p=0.78$ \\
\hline $0-5 \mathrm{~h}$ (ratio) & $0.0014 \pm 0.0004$ & $0.0017 \pm 0.0010$ & $0.0004 \pm 0.0010$ & $0.0013 \pm 0.0002$ & $0.0013 \pm 0.0010$ & $0.0001 \pm 0.0010$ & $p=0.72$ \\
\hline \multicolumn{8}{|c|}{ Colonic permeability } \\
\hline $0-5$ h $(\%)$ & $1.3910 \pm 0.2642$ & $1.2620 \pm 0.3510$ & $-0.1292 \pm 0.5634$ & $1.4440 \pm 0.4707$ & $1.0520 \pm 0.2723$ & $-0.3920 \pm 0.4739$ & $p=0.72$ \\
\hline $0-5 \mathrm{~h}$ (ratio) & $0.0863 \pm 0.0208$ & $0.0833 \pm 0.0238$ & $-0.0030 \pm 0.0333$ & $0.0817 \pm 0.0706$ & $0.0490 \pm 0.0083$ & $-0.0327 \pm 0.0197$ & $p=0.43$ \\
\hline $6-24 \mathrm{~h}(\%)$ & $6.4160 \pm 0.8898$ & $6.3550 \pm 2.718$ & $-0.0608 \pm 2.8890$ & $5.4930 \pm 1.0450$ & $3.1860 \pm 1.2270$ & $-2.3070 \pm 0.9152$ & $p=0.42$ \\
\hline 6-24 h (ratio) & $0.5011 \pm 0.0905$ & $0.4764 \pm 0.1703$ & $-0.0248 \pm 0.2078$ & $0.3616 \pm 0.0694$ & $0.2121 \pm 0.0910$ & $-0.1496 \pm 0.0826$ & $p=0.55$ \\
\hline
\end{tabular}

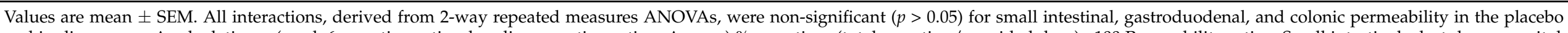

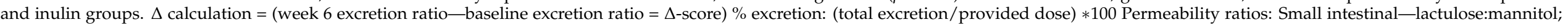
Gastroduodenal—sucrose:mannitol; Colonic—sucralose:mannitol. 


\section{Discussion}

The new finding of the present pilot study is that supplementation with inulin did not alter peripheral insulin sensitivity or skeletal muscle metabolic flexibility despite increases in gut Bifidobacteria. Intestinal permeability and endotoxin concentrations did not change following the intervention. The reduction in fasting insulin concentrations and HOMA-IR with inulin supplementation appears to be associated with higher baseline levels.

The improvement in HOMA-IR, an index of hepatic insulin resistance [47] following inulin supplementation is consistent with some [48,49] but not all prior studies $[21,22,50,51]$. The mechanism(s) responsible is(are) unclear; short-chain fatty acids produced via gut bacteria fermentation of dietary fibers have been implicated $[47,50]$. However, the greater reduction in HOMA-IR in the inulin group is difficult to interpret and may have been confounded by the corresponding higher baseline levels in this group compared with placebo. Taken together, our findings suggest that inulin supplementation had no obvious impact on peripheral insulin sensitivity, but the impact on HOMA-IR in adults with overweight and obesity at increased risk of T2D in the present study is unclear.

Compared to previous studies, our data support that fasting insulin concentration declined following inulin supplementation [21,49], however, a multitude of studies did not observe this trend [22,48,50-53]. Although the metabolic impacts of inulin consumption have not been fully elucidated, a reduction in insulin secretion, an increase in insulin clearance, or both may have contributed. The higher baseline insulin concentration, as described for HOMA-IR, is similarly difficult to interpret. Nevertheless, AIRg did not change following inulin supplementation in the present study, suggesting that perhaps enhanced insulin clearance was responsible for the reduction in fasting insulin concentrations. Future studies will be necessary to test this hypothesis and should consider the addition of satiety hormone measurements and c-peptide assays to further differentiate changes in insulin secretion versus clearance.

The inulin dosage selected for this study was based upon the reproducibility of its bifidogenic effect and tolerability (e.g., minimization of gastrointestinal distress, which may induce gut dysbiosis) $[16,54,55]$. The doses utilized in previous studies ranged from $10 \mathrm{~g} / \mathrm{d}$ to $30 \mathrm{~g} / \mathrm{d}$, but there was no clear pattern of a dose-response effect. Our participants were categorized as overweight/obese and were considered at high risk for T2D based upon the ADA risk screener [2]. In addition, body weight was kept stable during the controlled feeding intervention to avoid the potential impact of weight loss on insulin sensitivity. Findings on the direction of change for weight loss and glucose homeostasis with inulin supplementation were mixed with some studies reporting concurrent improvements in body weight and insulin sensitivity [21,49], while others report no change in body weight [48] or did not report body weight at all [55-57]. Although we observed that HOMA-IR declined in the absence of weight loss, these changes were diminished after correcting for baseline values. While there may be a small impact of inulin supplementation, we cannot exclude the possibility that the reduction in HOMA-IR was due to regression to the mean.

There were no changes in intestinal permeability, endotoxin concentrations (lipopolysaccharide binding protein), or in vivo substrate oxidation following inulin supplementation in the present study despite a significant bifidogenic effect. The lack of impact of inulin supplementation on intestinal permeability and endotoxin concentrations is inconsistent with prior studies [49,58]. The reasons for this are not clear. Dehghan et al. [49] reported a reduction in endotoxin concentration following inulin supplementation in women with T2D, suggesting intestinal permeability may have been reduced. As such, one possibility is that because our participants were relatively healthy (i.e., did not have impaired glucose tolerance or T2D) there was less to intervene upon. However, Russo et al. [59] reported that supplementation with inulin-enriched pasta reduced intestinal permeability and zonulin concentrations and increased glucagon-like peptide 2 in healthy adults; there was no change in these variables following supplementation with the control pasta. Future studies will be necessary to clarify this issue. 
The strengths of our investigation include the rigorous RCT design with controlled feeding, high participant retention rate and compliance to the controlled diet. As intended, the participant PA levels and both body weight and composition did not change over the course of the study. In addition, the inulin supplementation at a dosage of $10 \mathrm{~g} / \mathrm{d}$ produced a significant increase in Bifidobacteria and was well-tolerated by the participants. However, we acknowledge the limitations of this trial as well, including that the sample size was small due to substantial recruitment costs, racially homogenous, and most participants were female. Furthermore, our ability to fully sequence the gut microbiome was compromised by budgetary considerations. Future studies will require larger and more heterogenous samples. In addition, most participants were included based upon scores from the ADA risk screener rather than prediabetes clinical criteria. Although they were classified as overweight or obese and at increased risk for T2D, our participants were relatively healthy; this may have impacted the outcome of the study.

\section{Implications for the Future}

Our interim analysis indicated that the effect size for the change in peripheral insulin sensitivity was much smaller in magnitude $(0.21)$ than originally estimated. With this effect size, 564 participants would be required to detect group differences in our primary outcome. Thus, our trial was terminated at the end of the funding period. Although not our primary or secondary aim, given the pilot nature of this research, it is worthwhile to address several aspects of trial design feasibility, including recruitment, retention, controlled diet delivery, adherence to outpatient controlled feeding, and tolerability of inulin dosage [26]. Participant retention was high at $92 \%$, despite the high participant burden associated with controlled feeding, such as multiple weekly visits to the metabolic kitchen for body weight assessment and food pickup. Costs for delivering the controlled diets were consistent with that budgeted. Dietary adherence according to food return weigh-backs was high with $\sim 98 \%$ of foods provided consumed, and weight stability was maintained as intended. The tolerability of the inulin dosage used was supported with only one inulin group participant reporting mild GI side effects. However, recruitment feasibility was challenged by the screening criteria and higher-than-anticipated costs for participant enrollment (\$333 per participant randomized), which suggests the need for substantial recruitment budgeting for this type of trial. Given the rigorous controlled feeding design, high dietary compliance, and body weight stability, these findings and in particular, the effect size, suggest that largerscale studies in a similar study population may not be justified despite the demonstrated feasibility of most aspects of the study design.

\section{Conclusions}

Simple and effective dietary strategies are needed to reduce the incidence and prevalence of type 2 diabetes in the U.S. The findings from this pilot RCT suggest that inulin supplementation does not improve peripheral insulin sensitivity in adults at risk for T2D, at least when body weight and composition are stabilized with controlled feeding. Taken together with the relatively limited available evidence in adults at risk for T2D, the findings of our pilot RCT suggest that in the absence of weight loss there was no clear impact of inulin supplementation on glucose homeostasis. These findings call into question the need for larger-scale investigations in this study population.

Supplementary Materials: The following are available online at https:/ / www.mdpi.com/article / 10.3390/nu13093235/s1, Table S1. Controlled Diet Composition; Table S2. Habitual Physical Activity; Figure S1. Body Weight; Figure S2. IVGTT-Related Variables. (NOTE: for review, included in this file following the references).

Author Contributions: Conceptualization, K.P.D., B.M.D., A.P.N., M.A.P., M.W.H. and C.M.M.; formal analysis, C.M.M. and K.P.D.; investigation, K.P.D., B.M.D., M.W.H., A.P.N., M.A.P. and C.M.M.; data curation, C.M.M., K.P.D., R.P.M., A.P.N. and M.D.H.; writing-original draft preparation, C.M.M., K.P.D. and B.M.D.; review and editing, C.M.M., K.P.D., B.M.D., M.W.H., A.P.N., 
M.A.P., R.P.M. and M.D.H.; project administration, C.M.M. and K.P.D.; funding acquisition, K.P.D.; methodology, C.M.M., B.M.D., M.A.P., R.P.M., M.D.H., M.W.H., A.P.N. and K.P.D. All authors have read and agreed to the published version of the manuscript.

Funding: This research was funded by the National Institutes of Health R21 HL118668-01A1 and R21 HL118668-01A1S1.

Institutional Review Board Statement: This study was conducted according to the guidelines of the Declaration of Helsinki, and approved by the Institutional Review Board of Virginia Tech (protocol \# 13-694).

Informed Consent Statement: Informed consent was obtained from all subjects involved in the study.

Data Availability Statement: Data and materials are made available by request and at the discretion of the corresponding author.

Conflicts of Interest: The authors declare no conflict of interest.

\section{References}

1. Centers for Disease Control. National Diabetes Statistics Report. 2017. Available online: https://www.cdc.gov/diabetes/pdfs/ data/statistics/national-diabetes-statistics-report.pdf (accessed on 1 May 2018).

2. American Diabetes Association. Classification and diagnosis of diabetes. Diabetes Care 2015, 38, S8-S16. [CrossRef] [PubMed]

3. Eikenberg, J.D.; Davy, B.M. Prediabetes: A prevalent and treatable, but often unrecognized, clinical condition. J. Acad. Nutr. Diet. 2013, 113, 213-218. [CrossRef] [PubMed]

4. $\quad$ Perreault, L.; Pan, Q.; Mather, K.J.; Watson, K.E.; Hamman, R.F.; Kahn, S.E. Effect of regression from prediabetes to normal glucose regulation on long-term reduction in diabetes risk: Results from the Diabetes Prevention Program Outcomes Study. Lancet 2012, 379, 2243-2251. [CrossRef]

5. Tabák, A.G.; Herder, C.; Rathmann, W.; Brunner, E.; Kivimaki, M. Prediabetes: A high-risk state for diabetes development. Lancet 2012, 379, 2279-2290. [CrossRef]

6. Knowler, W.C.; Barrett-Connor, E.; Fowler, S.E.; Hamman, R.F.; Lachin, J.M.; Walker, E.A.; Nathan, D.M. Reduction in the incidence of type 2 diabetes with lifestyle intervention or metformin. N. Engl. J. Med. 2002, 346, 393-403. [CrossRef]

7. Hemmingsen, B.; Gimenez-Perez, G.; Mauricio, D.; Figuls, M.R.; Metzendorf, M.-I.; Richter, B. Diet, physical activity or both for prevention or delay of type 2 diabetes mellitus and its associated complications in people at increased risk of developing type 2 diabetes mellitus. Cochrane Database Syst. Rev. 2017, 12, CD003054. [CrossRef] [PubMed]

8. Cani, P.D.; Amar, J.; Iglesias, M.A.; Poggi, M.; Knauf, C.; Bastelica, D.; Neyrinck, A.M.; Fava, F.; Tuohy, K.M.; Chabo, C.; et al. Metabolic endotoxemia initiates obesity and insulin resistance. Diabetes 2007, 56, 1761-1772. [CrossRef]

9. Erridge, C.; Attina, T.; Spickett, C.M.; Webb, D.J. A high-fat meal induces low-grade endotoxemia: Evidence of a novel mechanism of postprandial inflammation. Am. J. Clin. Nutr. 2007, 86, 1286-1292. [CrossRef]

10. Cani, P.D.; Bibiloni, R.; Knauf, C.; Waget, A.; Neyrinck, A.M.; Delzenne, N.M.; Burcelin, R. Changes in gut microbiota control metabolic endotoxemia-induced inflammation in high-fat diet-induced obesity and diabetes in mice. Diabetes 2008, 57, 1470-1481. [CrossRef]

11. Tuttolomondo, A.; di Raimondo, D.; Pecoraro, R.; Arnao, V.; Pinto, A.; Licata, G. Atherosclerosis as an inflammatory disease. Curr. Pharm. Des. 2012, 18, 4266-4288. [CrossRef]

12. Creely, S.J.; McTernan, P.G.; Kusminski, C.M.; Fisher, F.M.; da Silva, N.F.; Khanolkar, M.; Evans, M.; Harte, A.L.; Kumar, S. Lipopolysaccharide activates an innate immune system response in human adipose tissue in obesity and type 2 diabetes. Am. J. Physiol. Endocrinol. Metab. 2007, 292, E740-E747. [CrossRef]

13. Pussinen, P.J.; Havulinna, A.S.; Lehto, M.; Sundvall, J.; Salomaa, V. Endotoxemia is associated with an increased risk of incident diabetes. Diabetes Care 2011, 34, 392-397. [CrossRef]

14. Frisard, M.I.; McMillan, R.P.; Marchand, J.; Wahlberg, K.A.; Wu, Y.; Voelker, K.A.; Heilbronn, L.; Haynie, K.; Muoio, B.; Li, L.; et al. Toll-like receptor 4 modulates skeletal muscle substrate metabolism. Am. J. Physiol. Metab. 2010, 298, E988-E998. [CrossRef]

15. Dehghan, P.; Gargari, B.P.; Asgharijafarabadi, M. Effects of high performance inulin supplementation on glycemic status and lipid profile in women with type 2 diabetes: A randomized, placebo-controlled clinical trial. Health Promot. Perspect. 2013, 3, 55-63. [CrossRef]

16. Meyer, D.; Stasse-Wolthuis, M. The bifidogenic effect of inulin and oligofructose and its consequences for gut health. Eur. J. Clin. Nutr. 2009, 63, 1277-1289. [CrossRef] [PubMed]

17. David, L.A.; Maurice, C.F.; Carmody, R.N.; Gootenberg, D.B.; Button, J.E.; Wolfe, B.E.; Ling, A.V.; Devlin, A.S.; Varma, Y.; Fischbach, M.A.; et al. Diet rapidly and reproducibly alters the human gut microbiome. Nature 2014, 505, 559-563. [CrossRef]

18. Simpson, H.L.; Campbell, B.J. Review article: Dietary fibre-microbiota interactions. Aliment. Pharmacol. Ther. 2015, 42, 158-179. [CrossRef] [PubMed] 
19. Aliasgharzadeh, A.; Khalili, M.; Mirtaheri, E.; Gargari, B.P.; Tavakoli, F.; Farhangi, M.A.; Babaei, H.; Dehghan, P. A combination of prebiotic inulin and oligofructose improve some of cardiovascular disease risk factors in women with type 2 diabetes: A randomized controlled clinical trial. Adv. Pharm. Bull. 2015, 5, 507-514. [CrossRef] [PubMed]

20. Dehghan, P.; Farhangi, M.A.; Tavakoli, F.; Aliasgarzadeh, A.; Akbari, A.M. Impact of prebiotic supplementation on T-cell subsets and their related cytokines, anthropometric features and blood pressure in patients with type 2 diabetes mellitus: A randomized placebo-controlled trial. Complement. Ther. Med. 2016, 24, 96-102. [CrossRef] [PubMed]

21. Guess, N.D.; Dornhorst, A.; Oliver, N.; Frost, G.S. A randomised crossover trial: The effect of inulin on glucose homeostasis in subtypes of prediabetes. Ann. Nutr. Metab. 2015, 68, 26-34. [CrossRef] [PubMed]

22. Guess, N.D.; Dornhorst, A.; Oliver, N.; Bell, J.D.; Thomas, E.L.; Frost, G.S. A randomized controlled trial: The effect of inulin on weight management and ectopic fat in subjects with prediabetes. Nutr. Metab. 2015, 12, 36. [CrossRef]

23. Mitchell, C.M.; Davy, B.M.; Halliday, T.; Hulver, M.W.; Neilson, A.P.; Ponder, M.A.; Davy, K.P. The effect of prebiotic supplementation with inulin on cardiometabolic health: Rationale, design, and methods of a controlled feeding efficacy trial in adults at risk of type 2 diabetes. Contemp. Clin. Trials 2015, 45, 328-337. [CrossRef]

24. Godin, G.; Shephard, R.J. Godin leasiure-time exercise questionnaire. Med. Sci. Sports Exerc. 1997, 29, S36.

25. Bang, H.; Edwards, A.M.; Bomback, A.S.; Ballantyne, C.M.; Brillon, D.; Callahan, M.A.; Teutsch, S.M.; Mushlin, A.I.; Kern, L.M. Development and validation of a patient self-assessment score for diabetes risk. Ann. Intern. Med. 2009, 151, 775-783. [CrossRef] [PubMed]

26. Eldridge, S.; Chan, C.; Campbell, M.; Bond, C.; Hopewell, S.; Thabane, L.; Lancaster, G. CONSORT 2010 statement: Extension to randomised pilot and feasibility trials. BMJ 2016, 355, i5239.

27. Bonnema, A.L.; Kolberg, L.W.; Thomas, W.; Slavin, J.L. Gastrointestinal tolerance of chicory inulin products. J. Am. Diet. Assoc. 2010, 110, 865-868. [CrossRef] [PubMed]

28. Boston, R.C.; Stefanovski, D.; Moate, P.; Sumner, A.E.; Watanabe, R.M.; Bergman, R.N. MINMOD millennium: A computer program to calculate glucose effectiveness and insulin sensitivity from the frequently sampled intravenous glucose tolerance test. Diabetes Technol. Ther. 2003, 5, 1003-1015. [CrossRef] [PubMed]

29. Marinik, E.L.; Frisard, M.I.; Hulver, M.W.; Davy, B.M.; Rivero, J.M.; Savla, J.S.; Davy, K.P. Angiotensin II receptor blockade and insulin sensitivity in overweight and obese adults with elevated blood pressure. Ther. Adv. Cardiovasc. Dis. 2013, 7, 11-20. [CrossRef]

30. Levy, J.; Matthews, D.R.; Hermans, M.P. Correct homeostasis model assessment (HOMA) evaluation uses the computer program. Diabetes Care 1998, 21, 2191-2192. [CrossRef] [PubMed]

31. Bergstrom, J. Percutaneous needle biopsy of skeletal muscle in physiological and clinical research. Scand J. Clin. Lab. Investig. 1975, 35, 609-616. [CrossRef]

32. Evans, W.J.; Phinney, S.D.; Young, V.R. Suction applied to a muscle biopsy maximizes sample size. Med. Sci. Sports Exerc. 1982, 14, 101-102. [CrossRef]

33. Hulver, M.W.; Berggren, J.R.; Carper, M.J.; Miyazaki, M.; Ntambi, J.M.; Hoffman, E.P.; Thyfault, J.P.; Stevens, R.; Dohm, G.L.; Houmard, J.A.; et al. Elevated stearoyl-CoA desaturase-1 expression in skeletal muscle contributes to abnormal fatty acid partitioning in obese humans. Cell Metab. 2005, 2, 251-261. [CrossRef] [PubMed]

34. Hulver, M.W.; Berggren, J.R.; Cortright, R.N.; Dudek, R.W.; Thompson, R.P.; Pories, W.J.; MacDonald, K.G.; Cline, G.W.; Shulman, G.I.; Dohm, G.L.; et al. Skeletal muscle lipid metabolism with obesity. Am. J. Physiol. Endocrinol. Metab. 2003, 284, E741-E747. [CrossRef]

35. Srere, P.A. Citrate synthase. Meth. Enzymol. 1969, 13, 3-26.

36. Smith, L. Spectrophotometric assay of cytochrome c oxidase. In Methods of Biochemical Analysis; Glick, D., Ed.; John Wiley \& Sons Inc.: Hoboken, NJ, USA, 1955; Volume 2, pp. 427-434.

37. Langendijk, P.S.; Schut, F.; Jansen, G.J.; Raangs, G.C.; Kamphuis, G.R.; Wilkinson, M.H.; Welling, G.W. Quantitative fluorescence in situ hybridization of Bifidobacterium spp. with genus-specific 16S rRNA-targeted probes and its application in fecal samples. Appl. Env. Microbiol. 1995, 61, 3069-3075. [CrossRef]

38. Martín, R.; Jiménez, E.; Heilig, H.; Fernández, L.; Marín, M.L.; Zoetendal, E.G.; Rodríguez, J.M. Isolation of bifidobacteria from breast milk and assessment of the bifidobacterial population by PCR-denaturing gradient gel electrophoresis and quantitative real-time PCR. Appl. Environ. Microbiol. 2009, 75, 965-969. [CrossRef]

39. Satokari, R.M.; Vaughan, E.E.; Akkermans, A.D.; Saarela, M.; de Vos, W.M. Bifidobacterial diversity in human feces detected by genus-specific PCR and denaturing gradient gel electrophoresis. Appl. Environ. Microbiol. 2001, 67, 504-513. [CrossRef]

40. Camilleri, M.; Nadeau, A.; Lamsam, J.; Nord, S.L.; Ryks, M.; Burton, D.; Sweetser, S.; Zinsmeister, A.R.; Singh, R. Understanding measurements of intestinal permeability in healthy humans with urine lactulose and mannitol excretion. Neurogastroenterol. Motil. 2009, 22, e15-e26. [CrossRef]

41. Dastych, M.; Dastych, M., Jr.; Novotna, H.; Cihalova, J. Lactulose/mannitol test and specificity, sensitivity, and area under curve of intestinal permeability parameters in patients with liver cirrhosis and Crohn's disease. Dig. Dis. Sci. 2008, 53, $2789-2792$. [CrossRef]

42. Farhadi, A.; Gundlapalli, S.; Shaikh, M.; Frantzides, C.; Harrell, L.; Kwasny, M.; Keshavarzian, A. Susceptibility to gut leakiness: A possible mechanism for endotoxaemia in non-alcoholic steatohepatitis. Liver Int. 2008, 28, 1026-1033. [CrossRef] [PubMed] 
43. Hilsden, R.J.; Meddings, J.B.; Sutherland, L.R. Intestinal permeability changes in response to acetylsalicylic acid in relatives of patients with Crohn's disease. Gastroenterology 1996, 110, 1395-1403. [CrossRef]

44. Rao, A.S.; Camilleri, M.; Eckert, D.J.; Busciglio, I.; Burton, D.D.; Ryks, M.; Wong, B.S.; Lamsam, J.; Singh, R.; Zinsmeister, A.R. Urine sugars for in vivo gut permeability: Validation and comparisons in irritable bowel syndrome-diarrhea and controls. Am. J. Physiol. Liver Physiol. 2011, 301, G919-G928. [CrossRef] [PubMed]

45. Grabitske, H.A.; Slavin, J.L. Gastrointestinal effects of low-digestible carbohydrates. Crit. Rev. Food Sci. Nutr. 2009, 49, 327-360. [CrossRef] [PubMed]

46. Faul, F.; Erdfelder, E.; Lang, A.-G.; Buchner, A. G* Power 3: A flexible statistical power analysis program for the social, behavioral, and biomedical sciences. Behav. Res. Methods 2007, 39, 175-191. [CrossRef]

47. Tripathy, D.; Almgren, P.; Tuomi, T.; Groop, L. Contribution of insulin-stimulated glucose uptake and basal hepatic insulin sensitivity to surrogate measures of insulin sensitivity. Diabetes Care 2004, 27, 2204-2210. [CrossRef] [PubMed]

48. Chambers, E.S.; Byrne, C.S.; Morrison, D.; Murphy, K.G.; Preston, T.; Tedford, C.; Garcia-Perez, I.; Fountana, S.; Serrano-Contreras, J.I.; Holmes, E.; et al. Dietary supplementation with inulin-propionate ester or inulin improves insulin sensitivity in adults with overweight and obesity with distinct effects on the gut microbiota, plasma metabolome and systemic inflammatory responses: A randomised cross-over trial. Gut 2019, 68, 1430-1438. [CrossRef] [PubMed]

49. Dehghan, P.; Gargari, B.P.; Jafarabadi, M.A.; Aliasgharzadeh, A. Inulin controls inflammation and metabolic endotoxemia in women with type 2 diabetes mellitus: A randomized-controlled clinical trial. Int. J. Food Sci. Nutr. 2014, 65, 117-123. [CrossRef]

50. Ghavami, A.; Roshanravan, N.; Alipour, S.; Barati, M.; Mansoori, B.; Ghalichi, F.; Nattagh-Eshtivan, E.; Ostadrahimi, A. Assessing the effect of high performance inulin supplementation via KLF5 mRNA expression in adults with type 2 diabetes: A randomized placebo controlled clinical trial. Adv. Pharm. Bull. 2018, 8, 39-47. [CrossRef]

51. Gargari, B.P.; Dehghan, P.; Aliasgharzadeh, A.; Jafar-Abadi, M.A. Effects of high performance inulin supplementation on glycemic control and antioxidant status in women with type 2 diabetes. Diabetes Metab. J. 2013, 37, 140-148. [CrossRef]

52. Baxter, N.T.; Schmidt, A.W.; Venkataraman, A.; Kim, K.S.; Waldron, C.; Schmidt, T.M. Dynamics of human gut microbiota and short-chain fatty acids in response to dietary interventions with three fermentable fibers. mBio 2019, 10, e02566-18. [CrossRef] [PubMed]

53. Causey, J.L.; Feirtag, J.M.; Gallaher, D.D.; Tungland, B.C.; Slavin, J.L. Effects of dietary inulin on serum lipids, blood glucose and the gastrointestinal environment in hypercholesterolemic men. Nutr. Res. 2000, 20, 191-201. [CrossRef]

54. Kolida, S.; Meyer, D.; Gibson, G.R. A double-blind placebo-controlled study to establish the bifidogenic dose of inulin in healthy humans. Eur. J. Clin. Nutr. 2007, 61, 1189-1195. [CrossRef]

55. Meng, X.; Zhang, G.; Cao, H.; Yu, D.; Fang, X.; de Vos, W.M.; Wu, H. Gut dysbacteriosis and intestinal disease: Mechanism and treatment. J. Appl. Microbiol. 2020, 129, 787-805. [CrossRef]

56. Farhangi, M.A.; Javid, A.Z.; Dehghan, P. The effect of enriched chicory inulin on liver enzymes, calcium homeostasis and hematological parameters in patients with type 2 diabetes mellitus: A randomized placebo-controlled trial. Prim. Care Diabetes 2016, 10, 265-271. [CrossRef]

57. Van Dokkum, W.; Wezendonk, B.; Srikumar, T.S.; van den Heuvel, E.G. Effect of nondigestible oligosaccharides on large-bowel functions, blood lipid concentrations and glucose absorption in young healthy male subjects. Eur. J. Clin. Nutr. 1999, 53, 1-7. [CrossRef] [PubMed]

58. Dehghan, P.; Gargari, B.P.; Jafarabadi, M.A. Oligofructose-enriched inulin improves some inflammatory markers and metabolic endotoxemia in women with type 2 diabetes mellitus: A randomized controlled clinical trial. Nutrition 2014, 30, 418-423. [CrossRef] [PubMed]

59. Russo, F.; Linsalata, M.; Clemente, C.; Chiloiro, M.; Orlando, A.; Marconi, E.; Chimienti, G.; Riezzo, G. Inulin-enriched pasta improves intestinal permeability and modifies the circulating levels of zonulin and glucagon-like peptide 2 in healthy young volunteers. Nutr. Res. 2012, 32, 940-946. [CrossRef] [PubMed] 